\title{
Comprehensive analysis of time- and dose-dependent patterns of gene expression in a human mesenchymal stem cell line exposed to low-dose ionizing radiation
}

\author{
YOUNG-WOO JIN ${ }^{1 *}$, YOUNG-JI NA ${ }^{2 *}$, YOUNG-JU LEE ${ }^{2}$, SUNGKWAN AN ${ }^{3}$, JUNG EUN LEE ${ }^{1}$, MEESEON JUNG ${ }^{1}$, \\ HEESUN KIM ${ }^{1}$, SEON YOUNG NAM ${ }^{1}$, CHA SOON KIM ${ }^{1}$, KWANG HEE YANG ${ }^{1}$, SEUNG UP KIM ${ }^{4}$, \\ WOO KYUNG KIM ${ }^{4}$, WOONG-YANG PARK ${ }^{2}$, KEUN-YOUNG YOO ${ }^{2,5}$, CHONG SOON KIM ${ }^{6}$ and JU HAN KIM ${ }^{2}$ \\ ${ }^{1}$ Division of Radiation Effect Research, Radiation Health Research Institute of KHNP, Seoul 132-703; ${ }^{2}$ Seoul National \\ University Biomedical Informatics (SNUBI), Seoul National University College of Medicine, Seoul 110-799; \\ ${ }^{3}$ Functional Genoproteome Research Center, Konkuk University, Seoul 143-701; ${ }^{4}$ Ajou University School of \\ Medicine, Suwon 442-721; ${ }^{5}$ National Cancer Center, Seoul 410-769; ${ }^{6}$ Korea Institute of \\ Radiological and Medical Sciences, Seoul 139-706, Korea
}

Received April 13, 2007; Accepted August 21, 2007

\begin{abstract}
We focused on the transcriptional responses induced by low and very low doses of ionizing radiation with time effect. Regardless of their importance only a few limited studies have been done. Here we applied a large-scale gene transcript profile to elucidate the genes and biological pathways. Immortalized human mesenchymal stem cells were irradiated with $0.01,0.05,0.2$ and 1 Gy of gamma radiation and total RNA was extracted from each cell line at 1 , 4, 12 and $48 \mathrm{~h}$ after exposure. The essential transcriptional responses were identified according to dose and time. A total of 6,016 genes showed altered expression patterns at more than one time point or dose level among the investigated 10,800 genes. Genes that showed dose-dependent expression responses were involved in signal transduction, regulation of transcription, proteolysis, peptidolysis and metabolism. Those that showed time-dependent responses were divided into two distinct groups: the up-and-down group was associated with 'cellular defense mechanisms' such as
\end{abstract}

Correspondence to: Dr Ju Han Kim, Seoul National University Biomedical Informatics (SNUBI), Seoul National University College of Medicine, 28 Yongon-dong, Chongno-gu, Seoul 110-799, Korea E-mail: juhan@snu.ac.kr

Dr Chong Soon Kim, Korea Institute of Radiological and Medical Sciences, 215-4 Gongneung-dong, Nowon-gu, Seoul 139-706, Korea E-mail: kjsoon@kirams.re.kr

*Contributed equally

Key words: low-dose radiation, gene expression, mesenchymal stem cell, microarray, dose response, time effect apoptosis, cell adhesion, stress response and immune response and the down-and-up group with 'fundamental cellular processes' such as DNA replication, mitosis, RNA splicing, DNA repair and translation initiation. Genes showing both dose-and time-dependent responses exhibited a mixture of both features. A highly non-linear relationship between the IR dose and the transcriptional relative response was obtained from the dose-dependent group. The timedependent group also exhibited a non-linear relationship as the complex effect group did. Some of the early-reactive-phase (1-4 h) genes showed a differential expression response to $0.01,0.05$ and $0.2 \mathrm{~Gy}$ but were unresponsive to $1 \mathrm{~Gy}$. Some of the late-recovery-phase (12-48 h) genes showed a differential expression to 1 Gy but were relatively unresponsive to other doses. We further characterized the gene expression patterns that could be implicated in the molecular mechanism of the cellular responses to low and very low-dose irradiation.

\section{Introduction}

An accurate estimation of the possible health risks associated with low doses of genotoxic components in the environment is an important challenge for public health sciences (1). Current models for estimating the risk of low-dose ionizing radiation (IR) commonly involve the linear non-threshold (LNT) model. The LNT model extrapolates empirical linear fits of human high-dose radiation data collected from survivors of atomicbomb explosions (2). In 1959, the International Commission on Radiological Protection (3) formulated regulations to protect occupationally exposed workers and the public from radiological hazards (4). Extrapolation using the LNT model may greatly overestimate the health risks of low-dose radiation and have a negative effect on public health by discouraging physicians from performing potentially useful radiological examinations such as CT scans (5). Luckey concluded that 'minute doses of IR benefited animal growth and development, fecundity, health and longevity' (6). Furthermore, debates on 
the adaptive response, the bystander effect and low-dose hypersensitivity have challenged the validity of the LNT model (7).

Cellular responses to IR are known to rely on the dynamic orchestration of complex regulatory pathways including cell cycle arrest, apoptosis, DNA damage and nucleotide excision repair. There is a growing demand for the identification of radiation-inducible genes. DNA microarray technology has made it possible to measure changes in the expression levels of thousands of genes and to study multiple cellular processes simultaneously and is, therefore, a useful tool for the study of radiation-induced cellular responses (8-10).

Previous microarray studies focused on gene expression changes induced either by a large dose of IR resulting in a high degree of cytotoxicity (11-17) or by a low dose of IR resulting in transcriptional alterations (18-23). There is an increasing concern about the hazardous effects caused by a 'very-low' $(<0.2$ Gy) dose of IR. While there are several large-scale gene expression studies for the differential effect between the high ( $>2$ Gy) and low (<2 Gy) dose of IR (24-27), there are fewer studies concerning the low and 'very-low' dose effects on gene expression. Moreover, most of the low or 'very-low' dose-based IR studies were performed at a single fixed time point following exposure without any consideration of the time-dependent experimental effects. To the best of our knowledge, there has been no systematic study of the differential time and dose effects of a 'very-low' dose of IR $(<0.5 \mathrm{~Gy})(28)$ using large scale gene expression profiling. Investigation of the differential time and dose effects of a 'very-low' dose of IR using a time-course based experimental design may help to clarify the LNT hypothesis.

In this study, we obtained global gene expression profiles of the B10 human mesenchymal stem cell (MSC) line using oligonucleotide DNA microarrays with a factorial design set at $1,4,12$ and $48 \mathrm{~h}$ after exposure to $0.01,0.05,0.2$ and $1 \mathrm{~Gy}$ of gamma radiation. Each experiment was triplicated to increase the reliability of the analysis. We identified and characterized genes that were induced or repressed following irradiation after different periods of time across different IR doses. Distinct patterns of gene expression were present in the early and late phase data set.

\section{Materials and methods}

Cell culture and exposure to IR. The B10 cell line used in this study is an immortalized, human bone marrow MSC line generated from human embryonic bone marrow tissues and immortalized using retroviral vectors encoding $v$-myc or the telomerase gene (29). B10 cells were grown in low glucose DMEM supplemented with 5\% FBS and penicillin/streptomycin at $37^{\circ} \mathrm{C}$ in a humidified incubator with a $5 \% \mathrm{CO}_{2}$ atmosphere. Cells were irradiated in triplicate at 0.01, 0.05, 0.2 or $1 \mathrm{~Gy}$ in a ${ }^{137} \mathrm{CS}$ irradiator (CIS Bio-international, dose rate $0.79 \mathrm{~Gy} / \mathrm{min}$ ) and harvested at $1,4,12$ or $48 \mathrm{~h}$ after IR exposure.

Labeling and hybridization for microarray analysis. The isolation of the total RNA from cells was carried out using a Trizol reagent (Invitrogen Inc., USA). Labeling of the total RNA was performed using the 3DNA submicro expression array detection kit (Genisphere, USA) according to the
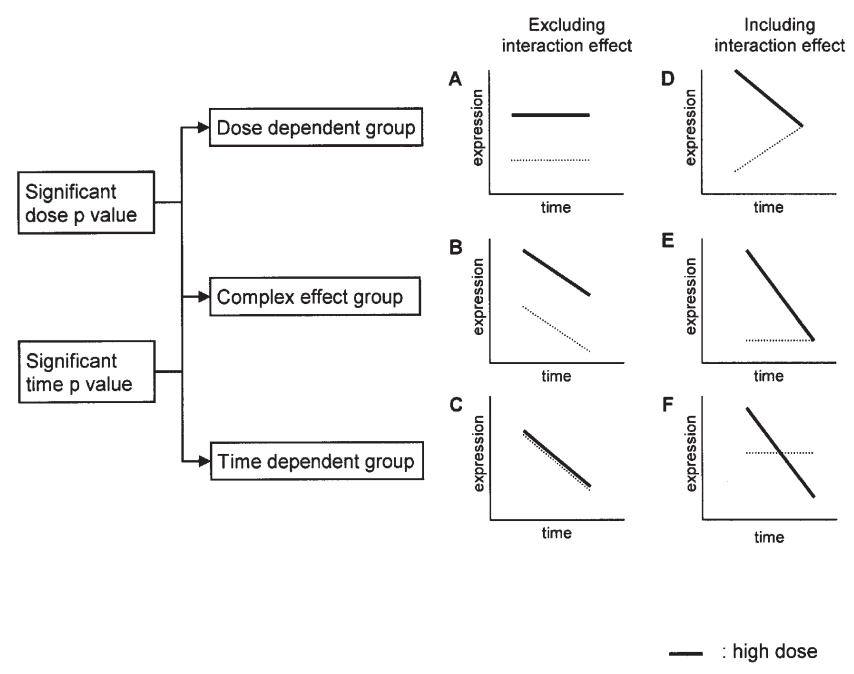

: low dose

Figure 1. A schematic diagram of the analysis for the selection and assignment of genes to dose- and/or time-dependent expression groups. A multi-factorial analysis was used to divide these genes into six categories. (A) The main effect of the dose is significant. (B) The main effects of both dose and time are significant. (C) The main effect of time is significant. (D) The main effect of the dose is significant but the main effect of time is not significant. The effect of the dose depends on time. (E) The main effects of both dose and time are significant. Both of the effects depend on each other. (F) The main effect of time is significant but the main effect of the dose is not significant. The effect of time depends on the dose.

manufacture's protocol. Briefly, total RNA was reverse transcribed using reverse transcription primers incorporating either Cy3- or Cy5-specific 3DNA capture sequences. The synthesized cDNAs were then fluorescently labeled using Cy3-3DNA or Cy5-3DNA depending on the complementary capture sequence. Changes in gene expression were assessed using the Mac Array-II Oligo-Human 10K (Macrogen, Korea) microarray chip with 10,800 probes. The hybridization of targets to specific probes was achieved by incubation in $2 \mathrm{X}$ formamide-based buffer ( $50 \%$ formamide, 8 X SSC, $1 \%$ SDS, $4 \mathrm{X}$ Denhardt's solution) at $70^{\circ} \mathrm{C}$ for $16 \mathrm{~h}$. After hybridization, the arrays were washed with $2 \mathrm{X} \mathrm{SSC}$ and $0.2 \% \mathrm{SDS}$ at $40^{\circ} \mathrm{C}$ for $15 \mathrm{~min}$, followed by a wash with $2 \mathrm{X} \mathrm{SSC}$ and another with $0.2 \mathrm{X} \mathrm{SSC}$ at room temperature for $15 \mathrm{~min}$ each. Images were analyzed using the GenePix4000B (Axon Instruments Inc., USA). The software automatically generated flags using the default settings for poor quality and missing spots and the assay was performed in triplicate for consistency.

Data analysis. We adhered to the MIAME (minimum information about a microarray experiment) standard (30) for our data analysis and storage. The raw data were stored and are available at the Xperanto database (31). Data were included for further analysis if the probe signal intensity was reliably detected (scored as 'present' by the statistical expression algorithm) in at least one of the samples within a dose series of IR. For each probe, the array signal intensities were normalized using the variance stabilizing normalization method introduced by Huber et al (32) with the vsn package in the Bioconductor (33). After performing intensity-dependent global Lowess regression, spatial and intensity-dependent effects were managed by pin group Lowess normalization. 
Table I. Number of significant IR-responsive genes in doseand/or time-dependent groups at different P-value cutoffs.

\begin{tabular}{lccc}
\hline P-value & $\begin{array}{c}\text { Dose-dependent } \\
\text { group }\end{array}$ & $\begin{array}{c}\text { Time-dependent } \\
\text { group }\end{array}$ & $\begin{array}{c}\text { Complex-effect } \\
\text { group }\end{array}$ \\
\hline 0.05 & 214 & 4,966 & 836 \\
$1 \mathrm{e}-2$ & 34 & 4,918 & 95 \\
$1 \mathrm{e}-6$ & - & 2,457 & - \\
\hline
\end{tabular}

A two-way analysis of variance (ANOVA) was applied to determine the time and dose effects and the differentially expressed sets of genes $(34,35)$ (Fig. 1). Statistical significance was adjusted by the Benjamini-Hochberg multiple-testing correction with false discovery rate (FDR) (36). Hierarchical clustering and self-organizing maps (SOM) (37) were performed using the Avadis 4.3 software package (Strand Life Sciences, India). The biological pathway and ontology-based analyses were performed by using an ArrayXPath (http:// www .snubi.org/software/ArrayXPath) $(38,39)$. Post-hoc, two-sample Student's t-tests were also performed. This statistical analysis was performed using an R statistical package (32) and default parameters were used when unspecified. Gene sets showing significant dose and/or time effects were separated for further analysis into groups classified as time-dependent, dosedependent or complex-effect (i.e., both time- and dose-dependent) groups (Fig. 1). These groups were then categorized into 'with' or 'without' interaction groups according to the significance of the interaction terms using a saturated linear model ('mean' plus 'dose effect' plus 'time effect' plus 'interaction').

\section{Results}

Global gene expression profiles. Table I shows the number of significant genes categorized into dose-dependent, timedependent and complex-effect groups according to two-way ANOVA with multiple-test correction by FDR. Most genes showed a time-dependent rather than dose-dependent response.
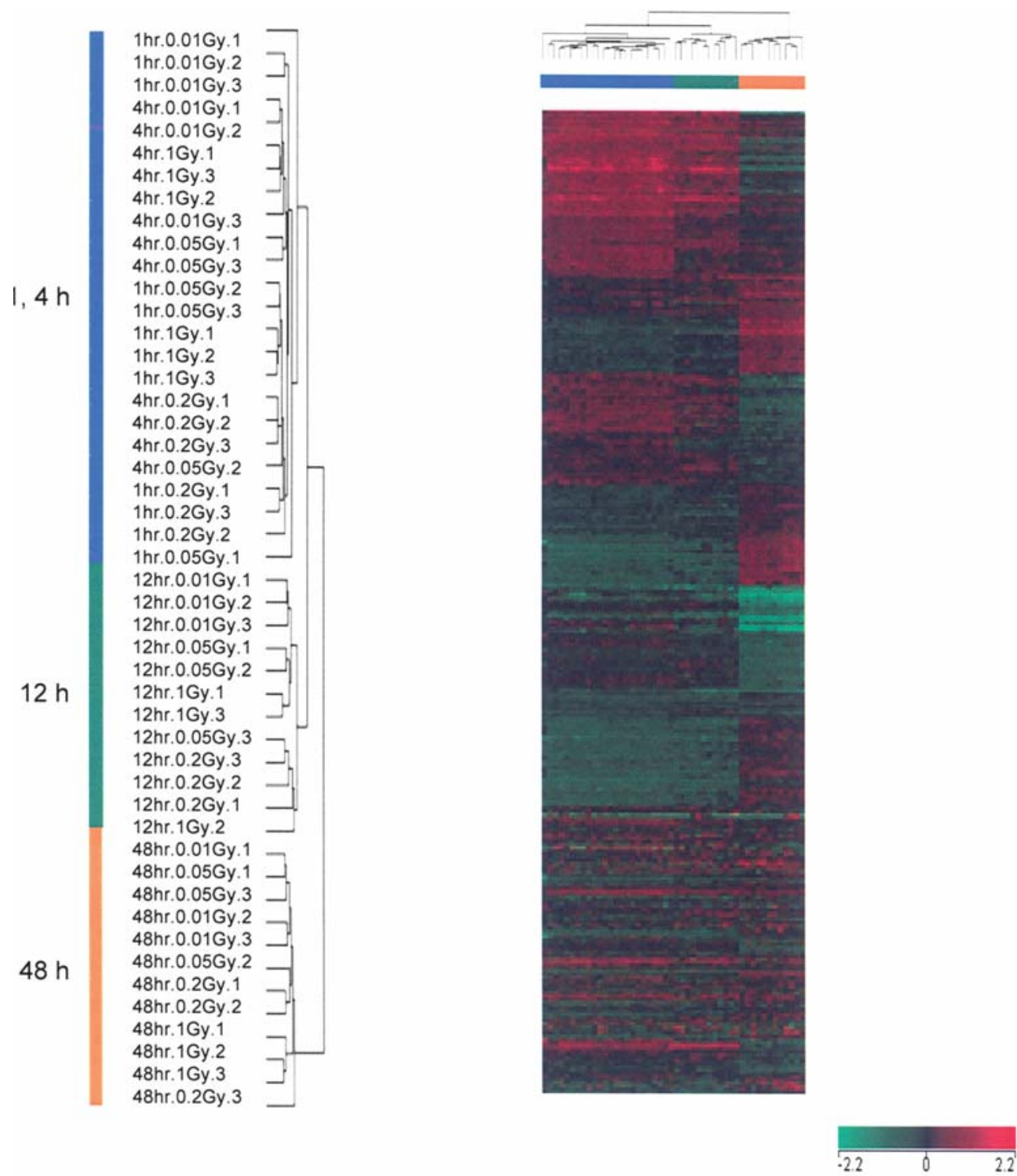

Figure 2. Hierarchical clustering analysis of the 6,016 genes by two-way ANOVA $(\mathrm{P}<0.05)$. The dendrogram at the top of the figure indicates the relationships between the different conditions as determined by the Avadis 4.3 software package (Strand Life Sciences, India). The red or green colors indicate a higher or lower expression, respectively, relative to the mean signal intensity. Each row represents a gene and each column a sample. 
A

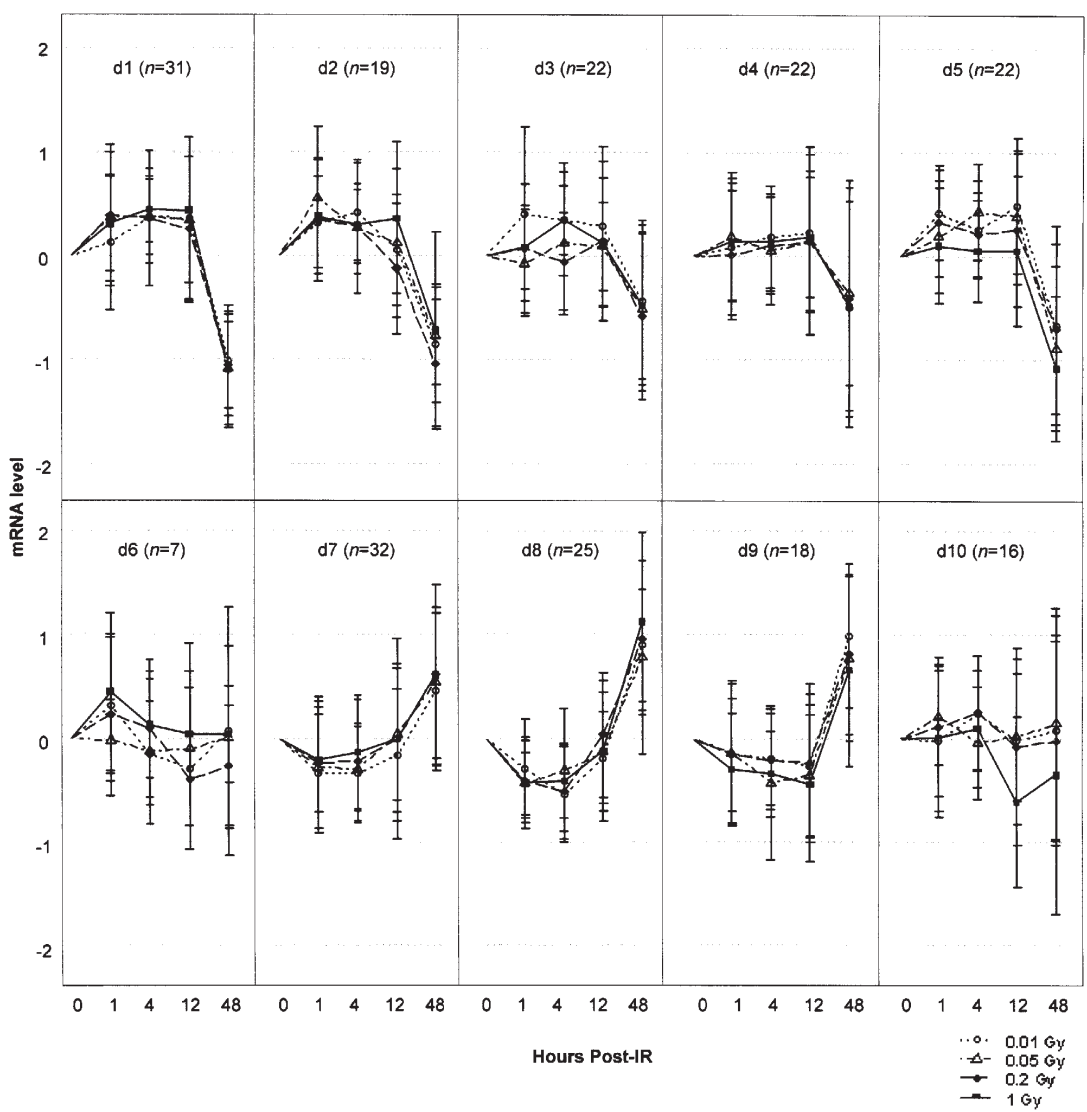

B

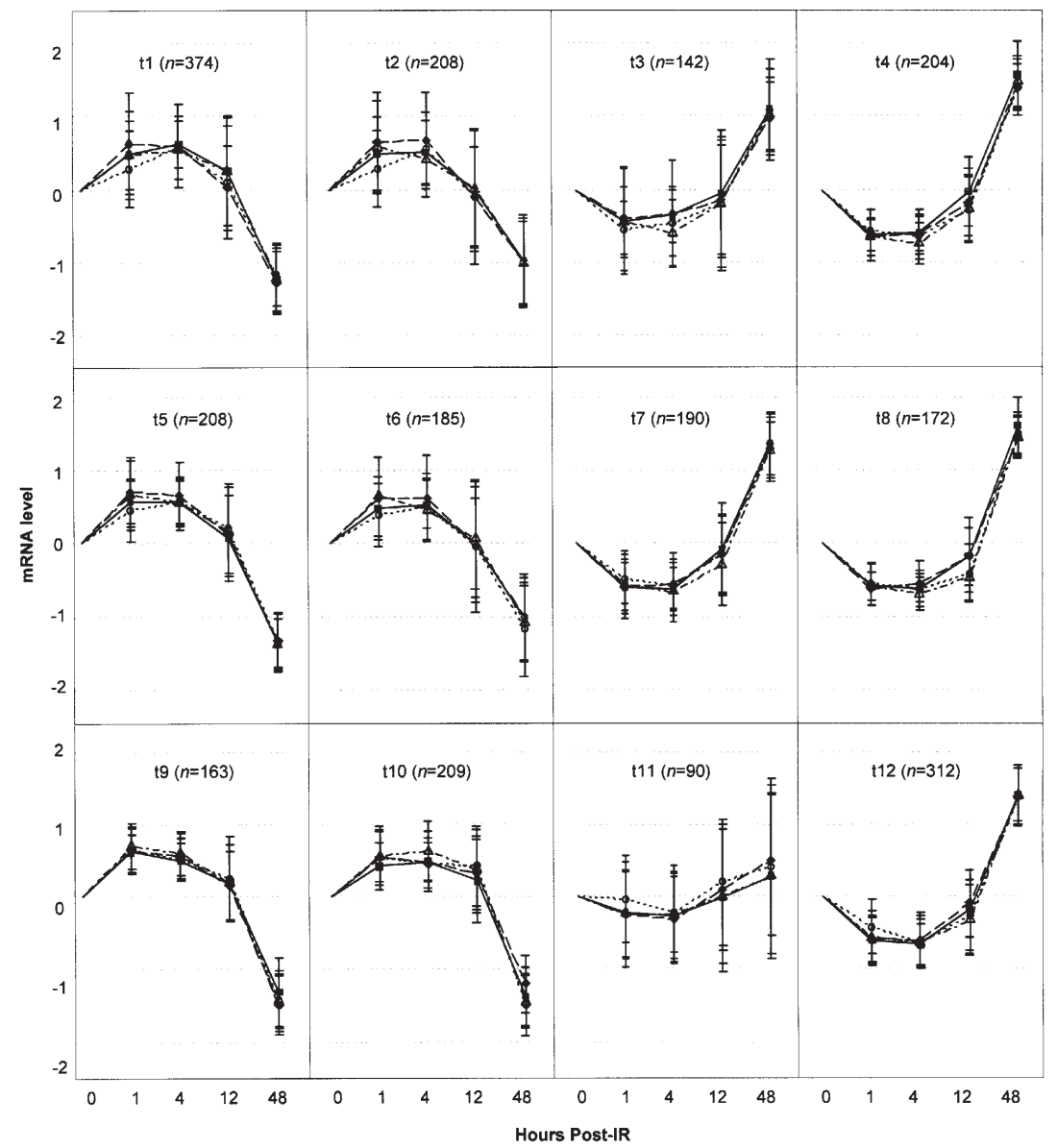

Hierarchical clustering of the genes showing a significant alteration by two-way ANOVA $(\mathrm{P}<0.05)$ revealed 3 specific time groups associated with the response (Fig. 2). In Fig. 2, the right group consists of the samples at 1 and 4 , the middle group at 12 and the left group at $48 \mathrm{~h}$ after exposure to IR. Within each time group, the dose effect remained persistent, while, overall, time effect appeared to be larger than the dose effect. Based on this result, we classified the time course into 
C

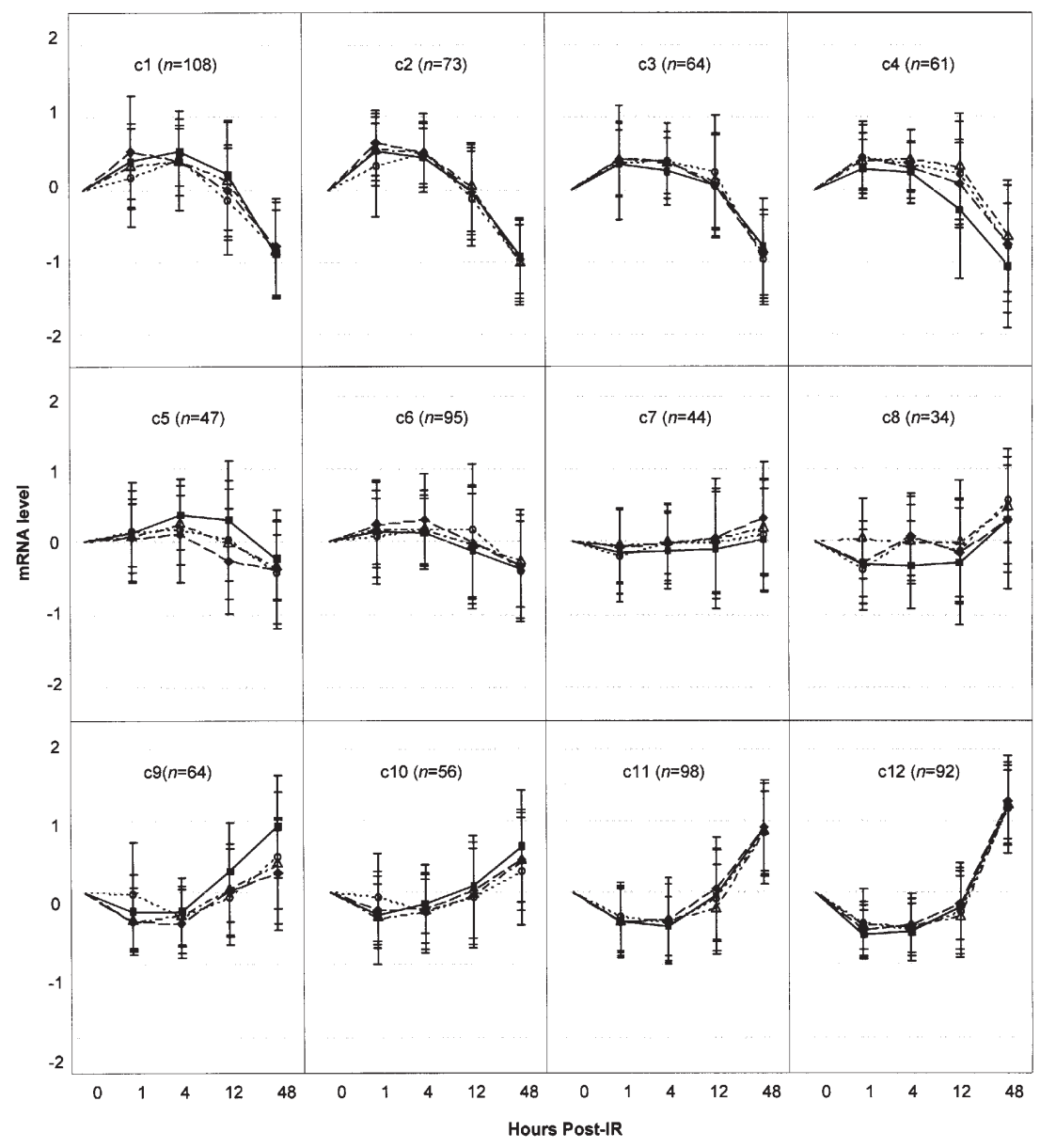

Figure 3. Gene expression patterns for dose- and/or time- dependent IR-responsive genes. Clusters were generated using self-organizing maps (Avadis 4.3). (A) Genes in the dose-dependent group were clustered into 10 clusters. (B) Genes in the time-dependent group were clustered into 12 clusters. (C) Genes in the complex-effect group were clustered into 12 clusters. The results represent the mean \pm standard error.

two phases consisting of the early reactive phase (ERP, i.e., 1 and $4 \mathrm{~h}$ ) and the late recovery phase (LRP, i.e., 12 and $48 \mathrm{~h}$ ).

Dose-dependent gene expression patterns. Dose-dependent genes were grouped into 10 clusters by SOM (Fig. 3A) and annotated by the gene ontology (GO) terms and biological pathways. Dose-dependent genes were mainly associated with the signal transduction pathway, the regulation of transcription, proteolysis, peptidolysis and metabolism (Table II). Cluster d 3 contained 22 genes that showed early up-regulation to $0.01 \mathrm{~Gy}$ but little response to other IR doses until $12 \mathrm{~h}$. The observed response was down-regulated at $48 \mathrm{~h}$ after exposure (Fig. 3A). The genes in cluster d3 were associated with carbohydrate metabolism, cell adhesion, cell proliferation, DNA-dependent regulation of transcription, G-protein coupled protein signaling pathway and other intracellular signaling cascades (Table II). Cluster d10 contained 16 genes showing down-regulation after $12 \mathrm{~h}$ of exposure to $1 \mathrm{~Gy}$ but no response to other doses. These genes were functionally associated with phosphorylation, control of skeletal myogenesis and signal-dependent regulation of myogenesis by corepressor MITR.

Time-dependent gene expression patterns. Time-dependent genes were grouped into 12 clusters by SOM (Fig. 3B).
Clusters were clearly divided into two distinct groups. While the clusters on the left side (i.e., clusters $\mathrm{t} 1, \mathrm{t} 2, \mathrm{t} 5, \mathrm{t} 6, \mathrm{t} 9$ and t10) showed up-regulation in the early phase and downregulation in the late phase, clusters on the right side (i.e., clusters $\mathrm{t} 3, \mathrm{t} 4, \mathrm{t} 7, \mathrm{t} 8, \mathrm{t} 11$ and $\mathrm{t} 12$ ) showed down-regulation in the early phase and then up-regulation in the late phase. While the 'up-and-down' clusters were significantly associated with apoptosis, cell adhesion, stress response, immune response and inflammation response, the 'down-andup' clusters were associated with DNA replication, mitosis, RNA splicing, DNA repair and translation initiation following functional enrichment analysis. It is possible that low-dose irradiation in the early phase may cause a temporary halt of fundamental cellular processes such as transcription and translation, along with an activation of cellular defense mechanisms associated with stress response. After $12 \mathrm{~h}$ of exposure, it is likely that cellular activities were resumed and defense systems were suppressed. For example, cluster t1 showed an association with activated cellular defense mechanisms in the early phase which included the TNF/Stressrelated signaling pathway, the IL-5 signaling pathway, eosinophils in the chemokine network of allergy responses, the first multivalent nuclear factor signaling pathway and skeletal muscle hypertrophy regulated via the AKT/mTOR pathway. 
Table II. Gene ontology and biological pathway-based enrichment analysis for dose-dependent group.

\begin{tabular}{|c|c|c|c|}
\hline Cluster & Gene & Biological pathway & GO biological process \\
\hline $\begin{array}{l}\mathrm{d} 1 \\
(\mathrm{n}=31)\end{array}$ & $\begin{array}{l}\text { GNAQ } \\
\text { IL12A } \\
\text { VIPR2 }\end{array}$ & $\begin{array}{l}\text { Activation of PKC through G-protein coupled receptor } \\
\text { IL-18 signaling pathway } \\
\text { Neuropeptides VIP and PACAP inhibit the apoptosis of activated T cells } \\
\text { PKC-catalyzed phosphorylation of inhibitory phosphoprotein of myosin phosphatase }\end{array}$ & $\begin{array}{l}\text { Cell adhesion } \\
\text { Cell-cell signaling } \\
\text { G-protein coupled receptor protein signaling pathway } \\
\text { Intracellular signaling cascade } \\
\text { Protein amino acid phosphorylation } \\
\text { Proteolysis and peptidolysis } \\
\text { DNA-dependent regulation of transcription } \\
\text { Signal transduction } \\
\text { Transport }\end{array}$ \\
\hline $\begin{array}{l}\mathrm{d} 2 \\
(\mathrm{n}=19)\end{array}$ & - & & - \\
\hline $\begin{array}{l}\mathrm{d} 4 \\
(\mathrm{n}=22)\end{array}$ & $\begin{array}{l}\text { MYD88 } \\
\text { NOTCH1 }\end{array}$ & 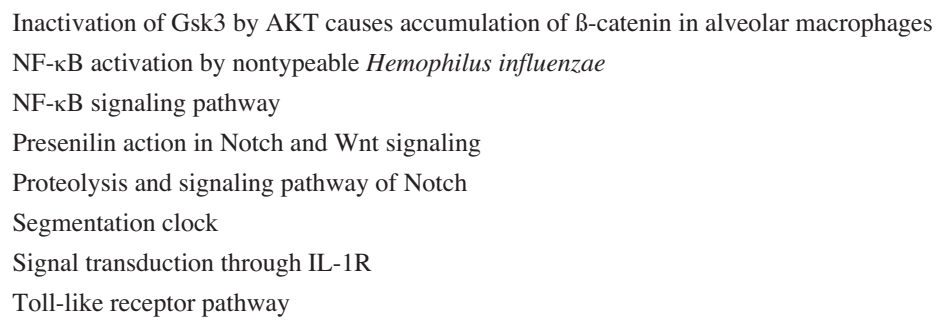 & $\begin{array}{l}\text { Cell differentiation } \\
\text { Cell growth and/or maintenance } \\
\text { Cell surface receptor linked signal transduction } \\
\text { Signal transduction }\end{array}$ \\
\hline $\begin{array}{l}\mathrm{d} 6 \\
(\mathrm{n}=7)\end{array}$ & BMPR2 & ALK in cardiac myocytes & Phosphorylation \\
\hline $\begin{array}{l}\mathrm{d} 7 \\
(\mathrm{n}=32)\end{array}$ & $\begin{array}{l}\text { IL12B } \\
\text { NUMA1 } \\
\text { PSMA4 } \\
\text { RING1 }\end{array}$ & $\begin{array}{l}\text { IL-18 signaling pathway } \\
\mathrm{NO}_{2} \text {-dependent IL-12 pathway in NK cells } \\
\text { PRC2 complex sets long-term gene silencing the modification of histone tails } \\
\text { Proteasome complex } \\
\text { Role of Ran in mitotic spindle regulation } \\
\text { Th1/Th2 differentiation }\end{array}$ & $\begin{array}{l}\text { Cell growth and/or maintenance } \\
\text { DNA-dependent regulation of transcription } \\
\text { Transport }\end{array}$ \\
\hline $\begin{array}{l}\mathrm{d} 8 \\
(\mathrm{n}=25)\end{array}$ & $\begin{array}{l}\text { CTBP1 } \\
\text { GABRA1 } \\
\text { GAD1 } \\
\text { HAND2 }\end{array}$ & $\begin{array}{l}\text { Biosynthesis of neurotransmitters } \\
\text { Cardiac protection against ROS } \\
\text { NFAT and hypertrophy of the heart } \\
\text { Sumoylation as a mechanism to modulate CtBP-dependent gene responses } \\
\text { WNT signaling pathway } \\
\gamma \text {-aminobutyric acid receptor life cycle }\end{array}$ & $\begin{array}{l}\text { Development } \\
\text { DNA-dependent regulation of transcription } \\
\text { Synaptic transmission }\end{array}$ \\
\hline d9 & CD5 & Cyclins and cell cycle regulation & \\
\hline$(\mathrm{n}=18)$ & CDKN2D & $\begin{array}{l}\text { Dendritic cells in regulating Th1 and Th2 development } \\
\text { G2/M checkpoint }\end{array}$ & DNA-dependent regulation of transcription \\
\hline $\begin{array}{l}\mathrm{d} 10 \\
(\mathrm{n}=16)\end{array}$ & MYOD1 & $\begin{array}{l}\text { Control of skeletal myogenesis by HDAC and calcium/calmodulin-dependent kinase } \\
\text { Signal-dependent regulation of myogenesis by corepressor MITR }\end{array}$ & Phosphorylation \\
\hline
\end{tabular}

Complex-effect gene expression patterns. Complex-effect genes were grouped into 12 clusters by SOM (Fig. 3C). Clusters showed mixed dose-and-time-dependent expression patterns and the functional enrichment analysis reflected the same tendency. For example, cluster $\mathrm{c} 4$ had 61 genes that were progressively induced at $0.01,0.05$ and 0.2 Gy of IR at 1,4 and 


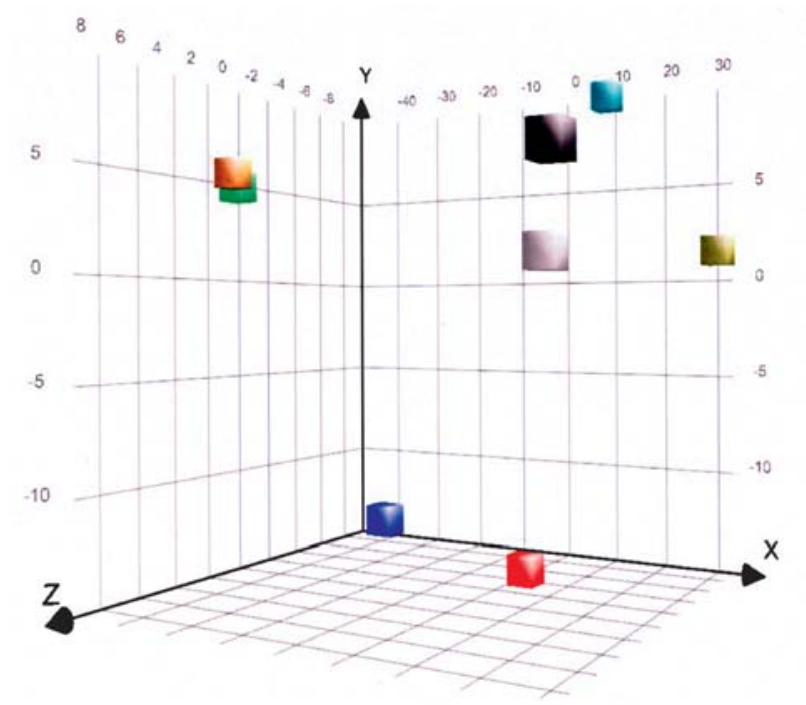

Figure 4. The principal component analysis of gene expression profiles at the early response phase (ERP) in the dose-dependent group. The gene expression pattern at each dose or at a time point is depicted as a dot in this three-dimensional graph.

$12 \mathrm{~h}$, while the induction declined modestly at $48 \mathrm{~h}$. Induction increased at 1 Gy from 1 to $4 \mathrm{~h}$ then rapidly decreased after $12 \mathrm{~h}$. The GO terms in the biological process category showing a significant enrichment by the hypergeometric test $(\mathrm{P}<1 \mathrm{e}-5)$ were signal transduction, induction of apoptosis, proteolysis, peptidolysis and electron transport. Cluster c9 contained 64 genes that were progressively repressed in response to all doses at 1 and $4 \mathrm{~h}$ of exposure, but were then induced modestly at $0.01,0.05$ and 0.2 Gy after $4 \mathrm{~h}$ of exposure up to $48 \mathrm{~h}$. The same genes were rapidly induced by $1 \mathrm{~Gy}$ of IR. A pathway analysis revealed that the genes were associated with apoptotic DNA fragmentation, tissue homeostasis, the IFN $\gamma$ signaling pathway, the IL-18 signaling pathway and regulators of bone mineralization.

Early-reactive-phase gene expression profile in the dosedependent group. Based on the finding that dose-specific effects were different between the early and the late response phases, we split the data into early reactive phase (ERP) and late recovery phase (LRP) datasets. Both datasets were reanalyzed using the same strategy including two-way ANOVA with FDR correction, SOM clustering and GO and pathway-based enrichment studies.

The eight groups (i.e., four dose and two early time points) with the triplicated ERP dataset were subjected to a principal component analysis (PCA), revealing three major components within the total variation among the samples (Fig. 4). PCA revealed three response groups of 0.01, 0.05 and 0.2 and $1 \mathrm{~Gy}$.
We created 12 clusters from the dose-dependent group as determined by two-way ANOVA with FDR correction $(\mathrm{P}<0.05)$ for the ERP dataset (Fig. 5A). A notable finding from the visual inspection of the expression patterns of the clusters in Fig. 5A was that, for many clusters, genes seemed to respond separately to the different three-dose groups determined by PCA (Fig. 4). Specifically, for clusters e1, e2, e3, e4, e6, e10, e11 and e12, the genes tended not to respond to $1 \mathrm{~Gy}$ while they responded differentially to 0.01 and to 0.05 and 0.2 Gy of IR (Fig. 5A). More specifically, the genes in clusters e1, e2, e3 and e4 showed up-regulation at 0.05 and $0.2 \mathrm{~Gy}$ and down-regulation at $0.01 \mathrm{~Gy}$. Those in clusters e6, e10, e11 and e12 showed up-regulation at $0.01 \mathrm{~Gy}$ and down-regulation at 0.05 and $0.2 \mathrm{~Gy}$ (Fig. 5A). Genes showing a dose-dependent response in the ERP group showed a tendency not to respond to $1 \mathrm{~Gy}$ of IR. This pattern was not found in the LRP dataset.

Late-recovery-phase gene expression profile in the dosedependent group. The LRP dataset was analyzed using the same strategy as the ERP dataset (Fig. 5B). In contrast to ERP, most of the clusters from the dose-dependent group in LRP showed a remarkable increase or decrease, probably due to the strong time effect in LRP. The PCA results showed a distinction between $1 \mathrm{~Gy}$ and the other doses of IR (data not shown). The grouping of 0.05 and $0.2 \mathrm{~Gy}$ found in ERP was not found in LRP. Instead, many clusters including 13, 14, 15, 18 and 110 showed a differential response to $1 \mathrm{~Gy}$ compared to the other doses (Fig. 5B). For example, cluster 15 contained 117 genes that showed down-regulation at $1 \mathrm{~Gy}$ but not at the other doses. The pathway analysis revealed that the genes in cluster 15 showed a significant association with the B-cell receptor signaling pathway, Fc Epsilon receptor I signaling in mast cells, the nitric oxide signaling pathway, the T-cell receptor signaling pathway and Wnt/LRP6 signaling. The clusters $13,14,15,18$ and 110 showing a distinctive response pattern to 1 Gy also showed a significant association with cyclins and cell cycle regulation, cell cycle: G1/S check point, CDK regulation of DNA replication, apoptotic DNA fragmentation and tissue homeostasis. Although other clusters did not show a distinctive response pattern to $1 \mathrm{~Gy}$, the pathway analysis showed that they were significantly related to the oxidative phosphorylation and electron transport chain. Oxidative phosphorylation has previously been reported to play a critical role in low-dose IR-induced adaptive responses (40). Our data suggest that genes which are responsive to a very low dose of IR are associated with adaptive responses at the later time points, while genes that are responsive to $1 \mathrm{~Gy}$ are associated with the cell cycle.

\section{Discussion}

We performed a systematic investigation on the gene expression patterns of a human mesenchymal stem cell line depending on dose and time in response to IR exposure using cDNA microarray technology. Our investigation focused on the transcriptional alteration induced by low and very lowdose IR exposure. We recognize significant genes that showed differential gene expression patterns in a dose-dependent manner, especially during the ERP. Exposure time is supposed 
A

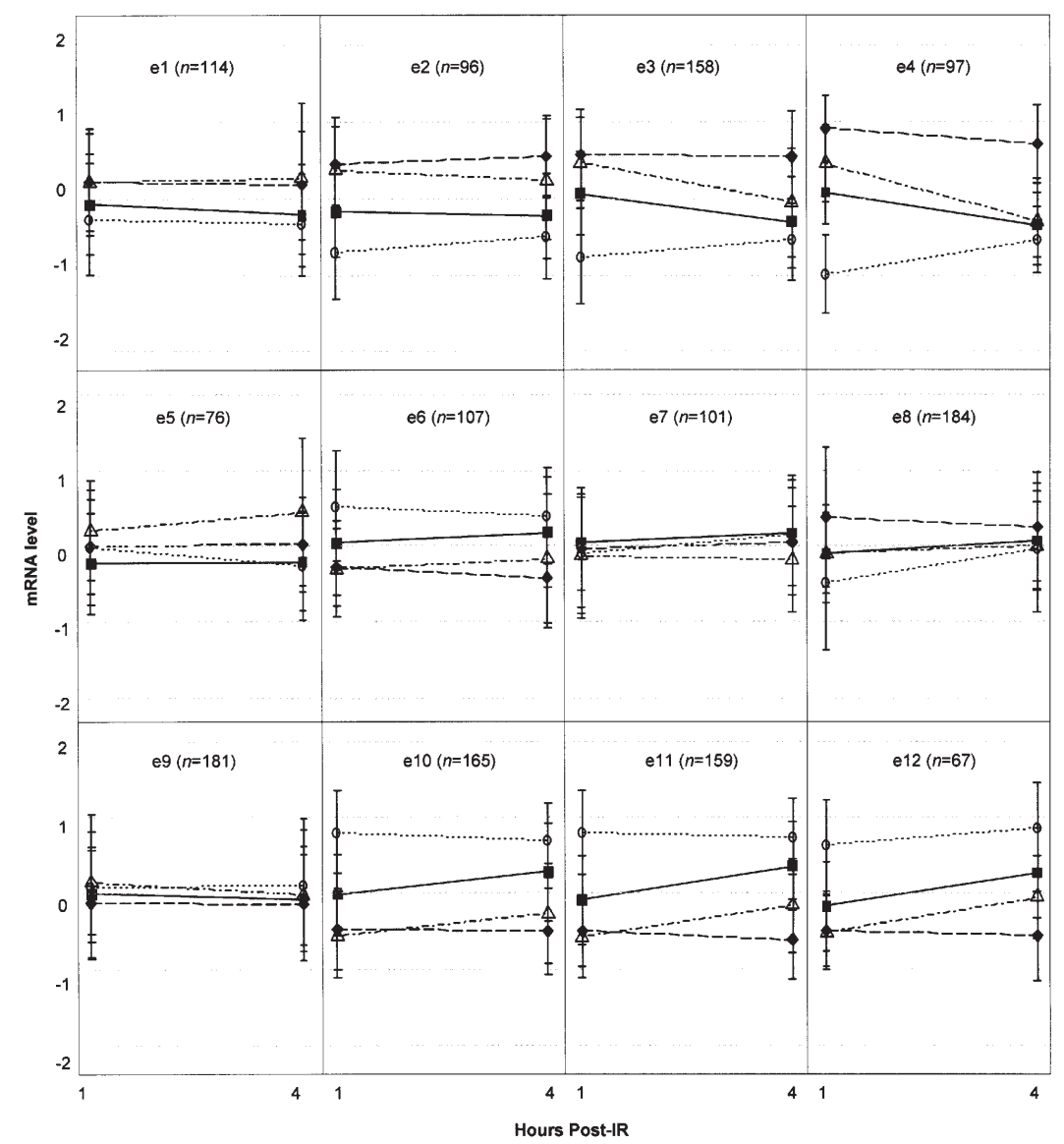

B

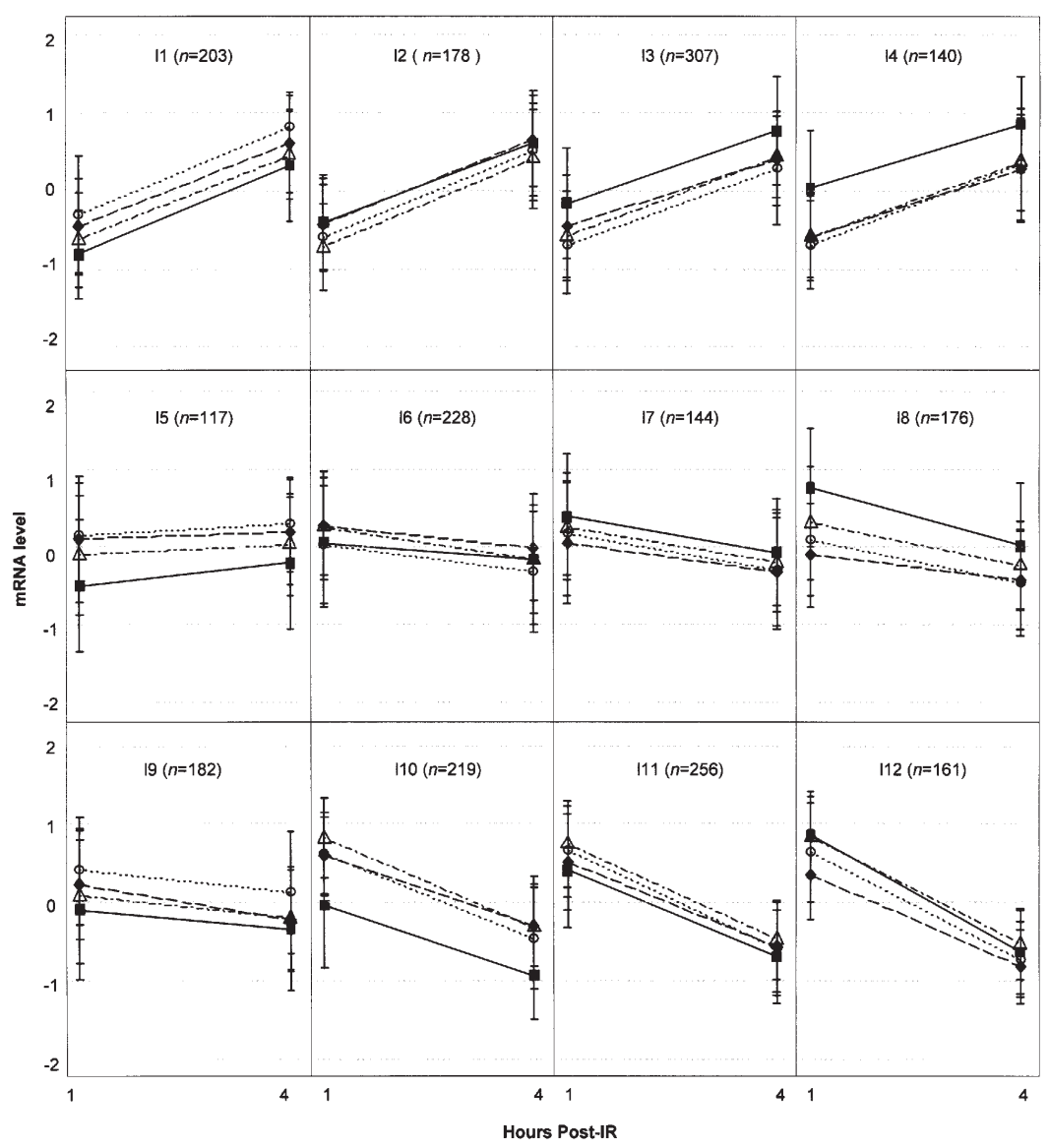

Figure 5. Gene expression patterns for dose-responsive genes at the early response phase (ERP) or late reactive phase (LRP). Clusters were generated using selforganizing maps (Avadis 4.3). (A) Cluster plot at ERP and (B) cluster plot at LRP in the dose-dependent group. The results represent the mean \pm standard error 
to have influence on gene expression profiles during the LRP more than the dose of IR delivered (Fig. 2). We expected the practical results on the dose and time effect to portray the molecular processes involved in cellular responses to gamma radiation.

The PCA analysis of the ERP showed three response groups to different doses of IR. However, we could not find the proportional relationship between the transcriptional changes and IR dose quantitatively. Moreover, genes that were upregulated at $0.01 \mathrm{~Gy}$ appeared to be down-regulated at both 0.05 and 0.2 Gy and vice versa. Notably the genes which responded during the ERP, hardly responded to the $1 \mathrm{~Gy}$ dose. This significant observation suggests that non-linear pattern of cellular responses with respect to the IR dose, which requires a pertinent model to predict such a pattern.

A highly non-linear relationship between the IR dose and the transcriptional relative response is identified in the $\mathrm{d} 1, \mathrm{~d} 2$, $\mathrm{d} 3$ and $\mathrm{d} 8$ clusters from the dose-dependent group. The timedependent group also exhibited a non-linear relationship similar to the complex-effect group. One noteworthy pattern of altered gene expression was the nonlinear relationship, especially with the dose change (Fig. 3).

Genes that showed a time-dependent response pattern (Fig. 3B) are associated with two distinguished groups, upand-down and down-and-up regulated genes. We speculated that the fundamental cellular processes in the ERP are seized temporarily by the external stimuli and defense mechanisms are activated as a counterpart. After $12 \mathrm{~h}$ of exposure to IR, we infer that cellular activities gradually resume and defense systems are down-regulated.

In irradiated mice, Yin et al showed that the expression levels of 1,574 out of 9,977 genes were altered in response to 0.1 and 2 Gy of IR (21). Approximately $30 \%$ of these genes were dose-responsive and $60 \%$ of them were responsive to exposure time. Here, we also found that gene expression after exposure to IR was strongly influenced by the exposure time (Table I). In a recent study, Ding et al reported that cytoskeleton components, ANLN and KRT15 and cell-cell signaling genes, GRAP2 and GPR51, were responsive to lowdose radiation but not to high-dose radiation (25). They suggested that these quantitative and qualitative responses in gene expression explained the non-linear correlation of the biological effects of IR from low-dose to high-dose exposure. We found that ANLN and KRT15 showed a time-dependent response and that GRAP2 showed a complex-effect pattern. ANLN plays a role in the spatial regulation of the contractile activity of myosin II in cytokinesis during cell proliferation and KRT15 encodes keratins which are a family of structurally related proteins that form intermediate filaments in epithelial cells. Cytoskeleton components seem to be affected by IR exposure time, which may cause a malfunction of the cell proliferation or formation of the protective epidermis.

We suggest that mRNA transcripts are highly expressed in response to both low-dose (0.01-0.2 Gy) and high-dose (1 Gy) IR exposure. Combining dose response with temporal profiles of gene expression identified novel sets of coordinately regulated genes. This study provides an intuitive idea about the molecular responses to physiologically relevant doses of IR that cannot be extrapolated from high-dose studies. Specifically, we investigated a low and very-low dose range study, which showed results that are different from previous studies. More feasible and practical investigations in low and very-low doses of IR are required to construct health risk assessment. Therefore, we recognized the non-linear relationship in dose effect. However, a novel, rigorous model to find the quantitative relationship between dose and expression level will be implemented in a further study.

\section{Acknowledgements}

This study was supported by a grant from the Korea Health $21 \mathrm{R}$ and D Project (03-PJ1-PG3-21000-0009) and Y.N's educational training was supported by a grant from the Korea Health $21 \mathrm{R}$ and D Project (A040163).

\section{References}

1. Mercier G, Berthault N, Mary J, Peyre J, Antoniadis A, Comet JP, Cornuejols A, Froidevaux C and Dutreix M: Biological detection of low radiation doses by combining results of two microarray analysis methods. Nucleic Acids Res 32: e12, 2004.

2. Mitchell SA, Marino SA, Brenner DJ and Hall EJ: Bystander effect and adaptive response in $\mathrm{C} 3 \mathrm{H}$ 10T1/2 cells. Int J Radiat Biol 80: 465-472, 2004.

3. ICRP: Recommendations of the International Commission on Radiological Protection. International Commission on Radiological Protection Publ 1. Pergamon Press, London, 1959.

4. ICRP: Principles for Limiting Exposure of the Public to Natural Sources of Radiation. Statement from the 1983 Washington Meeting of the ICRP. International Commission on Radiological Protection Publ 39. Pergamon Press, Oxford, 1984.

5. Tubiana M: Dose-effect relationship and estimation of the carcinogenic effects of low doses of ionizing radiation: the joint report of the Academie des Sciences (Paris) and of the Academie Nationale de Medecine. Int J Radiat Oncol Biol Phys 63: 317-319, 2005.

6. Luckey TD: Radiation Hormesis. CRC Press, Boca Raton, 1991.

7. Bonner WM: Low-dose radiation: Thresholds, bystander effects and adaptive responses. Proc Natl Acad Sci USA 100: 4973-4975, 2003.

8. Schena M, Shalon D, Davis RW and Brown PO: Quantitative monitoring of gene expression patterns with a complementary DNA microarray. Science 270: 467-470, 1995.

9. Schena M, Shalon D, Heller R, Chai A, Brown PO and Davis RW: Parallel human genome analysis: microarray-based expression monitoring of 1000 genes. Proc Natl Acad Sci USA 93: 10614-10619, 1996.

10. DeRisi J, Penland L, Brown PO, Bittner ML, Meltzer PS, Ray M, Chen Y, Su YA and Trent JM: Use of a cDNA microarray to analyse gene expression patterns in human cancer. Nat Genet 14: 457-460, 1996.

11. Khodarev NN, Park JO, Yu J, Gupta N, Nodzenski E, Roizman B and Weichselbaum RR: Dose-dependent and independent temporal patterns of gene responses to ionizing radiation in normal and tumor cells and tumor xenografts. Proc Natl Acad Sci USA 98: 12665-12670, 2001

12. Park WY, Hwang CI, Im CN, Kang MJ, Woo JH, Kim JH, Kim YS, Kim JH, Kim H, Kim KA, Yu HJ, Lee SJ, Lee YS and Seo JS: Identification of radiation-specific responses from gene expression profile. Oncogene 21: 8521-8528, 2002.

13. Amundson SA, Grace MB, McLeland CB, Epperly MW, Yeager A, Zhan Q, Greenberger JS and Fornace AJ Jr: Human in vivo radiation-induced biomarkers: Gene expression changes in radiotherapy patients. Cancer Res 64: 6368-6371, 2004.

14. Akerman GS, Rosenzweig BA, Domon OE, Tsai CA, Bishop ME, McGarrity LJ, MacGreqor JT, Sistare FD, Chen JJ and Morris SM: Alterations in gene expression profiles and the DNA damage response in ionizing radiation-exposed TK6 cells. Environ Mol Mutagen 45: 188-205, 2005.

15. Mahmoud-Ahmed AS, Atkinson S and Wong CS: Early gene expression profile in mouse brain after exposure to ionizing radiation. Radiat Res 165: 142-154, 2006. 
16. Jen KY and Cheung VG: Transcriptional response of lymphoblastoid cells to ionizing radiation. Genome Res 13: 2092-2100, 2003.

17. Amundson SA, Do KT, Vinikoor L, Koch-paiz CA, Bittner ML, Meltzer P, Trent JM and Fornace AJ Jr: Stress-specific signatures: expression profiling of p53 wild-type and -null human cells. Oncogene 24: 4572-4579, 2005.

18. Amundson SA, Lee RA, Koch-Paiz CA, Bittner ML, Meltzer P, Trent JM and Fornace AJ Jr: Differential responses of stress genes to low dose-rate g irradiation. Mol Cancer Res 1: 445-452, 2003.

19. Amundson SA, Do KT, Shahab S, Bittner M, Meltzer P, Trent J and Fornace AJ Jr: Identification of potential mRNA biomarkers in peripheral blood lymphocytes for human exposure to ionizing radiation. Radiat Res 154: 342-346, 2000.

20. Amundson SA, Bittner M, Meltzer P, Trent J and Fornace AJ Jr: Induction of gene expression as a monitor of exposure to ionizing radiation. Radiat Res 156: 657-661, 2001.

21. Yin E, Nelson DO, Coleman MA, Peterson LE and Wyrobek AJ: Gene expression changes in mouse brain after exposure to lowdose ionizing radiation. Int J Radiat Biol 79: 759-775, 2003.

22. Franco N, Lamartine J, Frouin V, Le Minter P, Petat C, Leplat JJ, Libert F, Gidrol X and Martin MT: Low-dose exposure to gamma rays induces specific gene regulations in normal human keratinocytes. Radiat Res 163: 623-635, 2005.

23. Lanza V, Pretazzoli V, Olivieri G, Pascarella G, Panconesi A and Negri R: Transcriptional response of human umbilical vein endothelial cells to low doses of ionizing radiation. J Radiat Res 46: 265-276, 2005.

24. Coleman MA, Yin E, Peterson LE, Nelson D, Sorensen K, Tucker JD and Wyrobek AJ: Low-dose irradiation alters the transcript profiles of human lymphoblastoid cells including genes associated with cytogenetic radioadaptive response. Radiat Res 164: 369-382, 2005.

25. Ding LH, Shingyoji M, Chen F, Hwang JJ, Burma S, Lee C, Cheng JF and Chen DJ: Gene expression profiles of normal human fibroblasts after exposure to ionizing radiation: A comparative study of low and high doses. Radiat Res 164: 17-26, 2005.

26. Kang CM, Park KP, Song JE, Jeoung DI, Cho CK, Kim TH, Bae SW, Lee SJ and Lee YS: Possible biomarkers for ionizing radiation exposure in human peripheral blood lymphocytes. Radiat Res 159: 312-319, 2003.

27. Wang HP, Long XH, Sun ZZ, Rigaud O, Xu QZ, Huang YC, Sui JL, Bai B and Zhou PK: Identification of differentially transcribed genes in human lymphoblastoid cells irradiated with $0.5 \mathrm{~Gy}$ of gamma ray and the involvement of low-dose radiation inducible CHD6 gene in cell proliferation and radiosensitivity. Int J Radiat Biol 82: 181-190, 2006.
28. Snyder AR and Morgan WF: Gene expression profiling after irradiation: Clues to understanding acute and persistent responses? Cancer Metastasis Rev 23: 259-268, 2004.

29. Kim SU: Human neural stem cells genetically modified for brain repair in neurological disorders. Neuropathology 24: 159-171, 2004.

30. Brazma A, Hinamp P, Quackenbush J, Sherlock G, Spellman P, Stoeckert C, Aach J, Ansorge W, Ball CA, Causton HC and Gaasterland T: Minimum information about a microarray experiment (MIAME)-toward standards for microarray data. Nat Genet 29: 365-371, 2001

31. Park JY, Park YR, Park CH, Kim JH and Kim JH: Xperanto: a web-based integrated system for DNA microarray data management and analysis. Genomics Informat 3: 24-29, 2005.

32. Huber W, von Heydebreck A, Sultmann H, Poustka A and Vingron M: Variance stabilization applied to microarray data calibration and to the quantification of differential expression. Bioinformatics 18: S96-S104, 2002.

33. Ihaka R and Gentleman R: A language for data analysis and graphics. J Comp Graph Stat 5: 299-314, 1996.

34. Ahmed AA, Vias M, Iyer NG, Caldas C and Brenton JD: Microarray segmentation methods significantly influence data precision. Nucleic Acids Res 32: e50, 2004.

35. Barrera L, Benner C, Tao YC, Winzeler E and Zhou Y: Leveraging two-way probe-level block design for identifying differential gene expression with high-density oligonucleotide arrays. BMC Bioinformatics 5: 42, 2004.

36. Benjamini Y and Hochberg Y: Controlling the false discovery rate: A practical and powerful approach to multiple testing. J R Stat Soc Ser B 57: 289-300, 1995.

37. Kohonen T: Self-organization maps. Springer-Verlag, Berlin, Heidelberg, 1995.

38. Chung HJ, Park CH, Han MR, Lee S, Ohn JH, Kim J, Kim J and Kim JH: ArrayXpathII: mapping and visualizing microarray gene-expression data with biomedical ontologies and integrated biological pathway resources using Scalable Vector Graphics. Nucleic Acids Res 33: W621-W626, 2005.

39. Chung HJ, Kim M, Park CH, Kim J and Kim JH: ArrayXpath: mapping and visualizing microarray gene-expression data with integrated biological pathway resources using Scalable Vector Graphics. Nucleic Acids Res 32: W460-W464, 2004.

40. Azzam EI, de Toledo SM and Little JB: Oxidative metabolism, gap junctions and the ionizing radiation-induced bystander effect. Oncogene 22: 7050-7057, 2003. 